\title{
Hospital admission for stroke or transient ischemic attack among First Nations people with diabetes in Ontario: a population-based cohort study
}

\author{
Moira K. Kapral MD MSc, Baiju R. Shah MD PhD, Michael E. Green MD MPH, Joan Porter MSc, \\ Rebecca Griffiths BSc, Eliot Frymire MA, Morgan Slater PhD, Kristen Jacklin PhD, Roseanne Sutherland, \\ Jennifer D. Walker PhD
}

See related research article at www.cmajopen.ca/lookup/doi/10.9778/cmajo.20190096

\section{Abstract}

Background: First Nations people have high rates of diabetes mellitus, which is a risk factor for stroke. We studied the rates of hospital admission, processes of care and outcomes of stroke and transient ischemic attack (TIA) in First Nations people in Ontario.

Methods: Using linked administrative databases, we identified annual cohorts of people aged 20-105 years in Ontario with prevalent diabetes between Apr. 1, 1995, and Mar. 31, 2015. We identified Status First Nations people in Ontario from the Indian Register. We compared age- and sex-standardized rates of hospital admission for stroke or TIA, processes of care and case fatality among First Nations versus other people in Ontario with diabetes.

Results: Overall, 28874 people with diabetes (of whom 536 were First Nations people) were admitted to hospital with a stroke or TIA between Apr. 1, 2011, and Mar. 31, 2016. Admission rates for stroke or TIA declined over the study period but were higher among First Nations people than other Ontarians in most years after 2005/06. First Nations people admitted with stroke or TIA were as likely as other Ontarians to undergo neuroimaging within 24 hours (94.6\% v. 96.0\%), be discharged to inpatient rehabilitation $(31.8 \%$ v. $34.8 \%)$ and receive carotid revascularization (1.4\% v. $2.7 \%)$, but were less likely to receive thrombolysis $(6.3 \%$ v. $11.0 \%)$. Age- and sex-standardized stroke case fatality was similar in First Nations people and other Ontarians at 7 days (12.0\% v. $8.5 \%$ ), 30 days (19.2\% v. $16.0 \%)$ and 1 year (33.8\% v. $28.1 \%)$.

Interpretation: Rates of hospital admission for stroke or TIA were higher among First Nations people than other people with diabetes in Ontario. Future work should focus on determining Indigenous-specific determinants of health related to this disparity and implementing appropriate interventions to mitigate the risks and sequelae of stroke in First Nations people.

troke is a leading cause of death and disability in Canada and worldwide. ${ }^{1}$ Diabetes mellitus is a risk factor for stroke and is also associated with an increased prevalence of other vascular risk factors including hypertension and hyperlipidemia. ${ }^{2-5}$ Stroke incidence is higher in Indigenous populations than in non-Indigenous populations in Australia, and, in Canada, diabetes occurs at a higher frequency and at an earlier age in First Nations people than in the general population. ${ }^{6-9}$ These increased risks are the result of a complex set of determinants of health, including contemporary and historic influences of colonization and marginalization experienced by First Nations people. ${ }^{10}$

In the setting of acute stroke, interventions such as thrombolysis, mechanical thrombectomy, stroke unit care and rehabilitation are associated with improved functional outcomes, and antithrombotic therapy, treatment of hyperlipidemia and hypertension, and carotid revascularization can decrease the risk of recurrent stroke and vascular death. ${ }^{11,12}$ However, many of these interventions require specialized stroke care resources that may not be available in all jurisdictions. First Nations people in Ontario are more likely than other Ontarians to live outside of urban settings, where these services are most readily accessed.

\section{Competing interests: None declared.}

This article has been peer reviewed.

Correspondence to: Moira Kapral, moira.kapral@uhn.ca

CMAJ Open 2020. DOI:10.9778/cmajo.20190199 
Little is known about the risks and outcomes of stroke among First Nations people with diabetes, and this information gap is of critical importance to First Nations leadership and health care providers, who are faced with high rates of diabetes in their populations. The aim of the present study was to compare hospital admissions for stroke, the processes of acute stroke care and stroke case fatality among First Nations people and other people with diabetes in Ontario.

\section{Methods}

\section{Setting}

This study was conducted in Ontario, Canada's most populous province, with an estimated population of 13 million. ${ }^{13}$ Provincial residents, including First Nations people, have universal access to hospital and physician services and diagnostic tests.

\section{Data sources and study cohort}

In collaboration with the Chiefs of Ontario, we used linked population-based administrative databases to form the study cohort of First Nations people and other Ontarians with diabetes described in Appendix 1 of the methods paper by Slater and colleagues. ${ }^{14}$ Briefly, annual cohorts of all Ontario residents aged 20-105 years with prevalent diabetes and alive on Mar. 31 of each year between Apr. 1, 1995, and Mar. 31, 2015, were identified from the Registered Persons Database linked with the Ontario Diabetes Database, and classified into 2 cohorts: First Nations and non-First Nations..$^{15}$ First Nations people were identified from the Indian Register, a registry maintained by Crown-Indigenous Relations and Northern Affairs Canada that lists all "Status/Registered" First Nations people who have registered with the federal government and are members of a First Nation recognized by the Government of Canada. Those not included in the Indian Register were classified as non-First Nations.

We then used the Discharge Abstract Database maintained by the Canadian Institute for Health Information to identify hospital admissions for stroke or transient ischemic attack (TIA) in each fiscal year ending Mar. 31, 2016, using International Classification of Diseases, 9th Revision (ICD-9) and International Statistical Classification of Diseases and Related Health Problems, 10th Revision, enhanced Canadian version (ICD-10-CA) diagnosis codes (Appendix 1, available at www. cmajopen.ca/content/8/1/E156/suppl/DC1). These codes have been validated, with agreement of $90 \%$ for ICD-9 and $92 \%$ for ICD-10-CA compared to chart abstraction. ${ }^{16}$

The data sets were linked by means of unique encoded identifiers and analyzed at ICES. If a person had more than 1 hospital admission for stroke or TIA in a fiscal year, only the first event was kept for analysis. We excluded records where the diagnosis of stroke or TIA was flagged as questionable. We did not include people who died from stroke before hospital presentation, those who never sought hospital care and those who were discharged from the emergency department without being admitted. For people included in the study cohort, we used Aggregated Diagnosis Groups (which aggregate and count the number of similar types of health conditions) as a measure of comorbidity. ${ }^{17}$

\section{Statistical analysis}

We used SAS version 9.4 software (SAS Institute) for statistical analyses.

Hospital admission for stroke or transient ischemic attack We calculated the crude rate of hospital admission for stroke or TIA in First Nations people (living in First Nations communities and outside of First Nation communities) and other people in Ontario, and stratified by sex and age group ( $\leq 30 \mathrm{yr}, 30-49 \mathrm{yr}, 50-79 \mathrm{yr}$ and $\geq 80 \mathrm{yr}$ ) between Apr. 1, 1996, and Mar. 31, 2016. We included both stroke and TIA in our analyses of hospital admission rates since TIA and minor stroke account for a large component of symptomatic cerebrovascular disease and represent important opportunities for prevention of larger, disabling strokes. ${ }^{18,19}$ However, we also performed secondary analyses stratified by event type (stroke or TIA).

For First Nations people and other people in Ontario, we calculated direct age- and sex-standardized rates and $95 \%$ confidence intervals (CIs) of admission for stroke or TIA per 100000 people with diabetes using the 2001 Ontario population aged 20 years or more with diabetes as the standard population. We calculated standardized rates for each year between Apr. 1, 1996, and Mar. 31, 2016.

\section{Processes of stroke care and outcomes}

In the sample of people with diabetes alive on Mar. 31, 2011, we identified those admitted to hospital for stroke or TIA between Apr. 1, 2011, and Mar. 31, 2017. Using this cohort of people with diabetes and stroke or TIA, we determined the proportion of people who underwent brain imaging, defined as computed tomography or magnetic resonance imaging scan within 24 hours of arrival at hospital. We then excluded those with TIA and studied the following processes of care and outcomes: thrombolytic therapy for ischemic stroke; carotid revascularization (endarterectomy or stenting) within 90 days of admission for ischemic stroke; discharge to inpatient rehabilitation following hospital admission for ischemic or hemorrhagic stroke; and death at 7, 30 and 365 days after admission for ischemic or hemorrhagic stroke.

We performed analyses of carotid revascularization, discharge destination and case fatality for the cohort admitted between Apr. 1, 2011, and Mar. 31, 2016, to allow for 1 year of follow-up for outcomes. We performed analyses of brain imaging and thrombolysis for the cohort admitted between Apr. 1, 2012, and Mar. 31, 2017, as these variables were available in administrative data only from 2012 onward. Outcome rates were age- and sex-standardized to the 2001 Ontario population aged 20 years or more with diabetes. Only the first stroke or TIA event a person had over the 5-year observation period was kept for analysis.

We determined whether a patient had received a computed tomography or magnetic resonance imaging scan or thrombolysis from the Discharge Abstract Database using a 
special project field that captures process measures specific to stroke and TIA. We determined rates of carotid revascularization using Canadian Classification of Health Intervention codes in the Discharge Abstract Database and allowing for 90 days of follow-up after stroke (see Appendix 1 for data sources and codes). We determined the proportion of people discharged to rehabilitation from the Discharge Abstract Database discharge disposition field. We used the Registered Persons Database, a repository of demographic information about all people in Ontario with a health card number, to determine all-cause mortality after stroke, regardless of location, and date of death, if applicable. The numerator was the number of deaths within each time frame (7, 30 and $365 \mathrm{~d}$ ), and the denominator was the number of hospital admissions for stroke within each fiscal year. We calculated survival time as the difference between the date of death and the date of admission to hospital.

\section{Ethics approval}

This work was done as a collaboration between First Nations and academic researchers, and was guided by the First Nations principles of ownership, control, access and possession. ${ }^{20}$ In addition to approval by the Chiefs of Ontario Data Governance Committee, the project was reviewed and approved by the research ethics boards of Queen's University and Laurentian University.

\section{Results}

Overall, 28874 people (of whom 536 were First Nations people) with diabetes were admitted to hospital with stroke or TIA between Apr. 1, 2011, and Mar. 31, 2016. Compared to other Ontarians with diabetes and stroke or TIA, First Nations people were younger (median age 63 yr v. 74 yr), more likely to be female $(53.5 \% \mathrm{v} .46 .8 \%)$ and more likely to live in rural areas (22.6\% v. $9.5 \%$ ) (Table 1$)$.

Hospital admission rates for stroke or TIA among all people with diabetes in Ontario declined between 1996/97 and 2015/16, from 1708 to 714/100 000 First Nations people and from 1395 to 517/100 000 other Ontarians. However, admission rates for stroke or TIA were higher among First Nations people than among other Ontarians in most years after 2006/ 07 (Figure 1).

In 2015/16, admission rates per 100000 were higher among First Nations people than among other Ontarians for those aged 30-49 years (271.0, 95\% CI 154.9-440.1 v. 99.0, 95\% CI 85.3-114.2) and 50-64 years (776.4, 95\% CI 605.2980.9 v. 281.8 , $95 \%$ CI 266.5-297.8) but were similar for those aged 65 years or more (Table 2). Admission rates for stroke or TIA were similar among men and women for both First Nations people and other Ontarians. In analyses stratified by event type, admission rates were higher for First Nations people than for other Ontarians for both stroke alone and TIA alone (Table 2).

First Nations people with stroke or TIA were as likely as other Ontarians to undergo neuroimaging within 24 hours of hospital arrival $(94.6 \%$ v. $96.0 \%)$, to be discharged to inpa-

\begin{tabular}{|c|c|c|}
\hline \multicolumn{3}{|c|}{$\begin{array}{l}\text { Table 1: Characteristics of First Nations people and other } \\
\text { people in Ontario with diabetes admitted to hospital with } \\
\text { stroke or transient ischemic attack in Ontario, Apr. 1, 2011, to } \\
\text { Mar. } 31,2016\end{array}$} \\
\hline \multirow[b]{2}{*}{ Characteristic } & \multicolumn{2}{|c|}{ No. $(\%)$ of people* } \\
\hline & $\begin{array}{l}\text { First Nations } \\
\text { people with } \\
\text { diabetes } \\
n=536\end{array}$ & $\begin{array}{l}\text { Other people in } \\
\text { Ontario with } \\
\text { diabetes } \\
n=28338\end{array}$ \\
\hline Age, yr, median (IQR) & $63(55-71)$ & $74(65-81)$ \\
\hline \multicolumn{3}{|l|}{ Age group, yr } \\
\hline $20-49$ & 66 (12.3) & $1065(3.8)$ \\
\hline $50-64$ & $231(43.1)$ & $5841(20.6)$ \\
\hline $65-79$ & $190(35.4)$ & $12564(44.3)$ \\
\hline$\geq 80$ & $49(9.1)$ & $8868(31.3)$ \\
\hline Female sex & $287(53.5)$ & $13274(46.8)$ \\
\hline \multicolumn{3}{|l|}{ Rurality } \\
\hline Urban & $151(28.2)$ & 19265 (68.4) \\
\hline Semiurban & $90(16.8)$ & $6203(22.0)$ \\
\hline Rural & $121(22.6)$ & $2680(9.5)$ \\
\hline Missing & $174(32.5)$ & $190(0.7)$ \\
\hline \multicolumn{3}{|l|}{ Comorbidity } \\
\hline Low ( $\leq 4$ ADGs) & $67(12.5)$ & $3158(11.1)$ \\
\hline Medium (5-9 ADGs) & $173(32.3)$ & 9979 (35.2) \\
\hline High ( $\geq 10$ ADGs) & $296(55.2)$ & $15201(53.6)$ \\
\hline \multicolumn{3}{|l|}{ Stroke type } \\
\hline Hemorrhagic & $55(10.3)$ & $3203(11.3)$ \\
\hline Ischemic & $372(69.4)$ & 20854 (73.6) \\
\hline Transient ischemic attack & $109(20.3)$ & $4281(15.1)$ \\
\hline \multicolumn{3}{|c|}{$\begin{array}{l}\text { Note: ADGs = Aggregated Diagnosis Groups (used as a measure of comorbidity) } \\
\text { IQR = interquartile range. } \\
\text { "Except where noted otherwise. } \\
\text { †Defined according to the Rurality Index for Ontario. }{ }^{21}\end{array}$} \\
\hline
\end{tabular}

tient rehabilitation $(31.8 \%$ v. 34.8$)$ and to undergo carotid revascularization for ischemic stroke or TIA (1.4\% v. $2.7 \%)$ but were less likely to receive thrombolysis for ischemic stroke (6.3\%, 95\% CI 3.9-9.7 v. 11.0\%, 95\% CI 10.3-11.7) (Table 3).

Point estimates for age- and sex-standardized stroke case fatality were higher among First Nations people than among other Ontarians at 7 days $(12.0 \%$ v. $8.5 \%), 30$ days $(19.2 \%$ v. $16.0 \%)$ and 1 year (33.8\% v. $28.1 \%)$, but the CIs overlapped for all estimates. In analyses of 1-year case fatality stratified by age, the point estimates for mortality for First Nations people were higher than for other Ontarians among those aged $30-49$ years $(28.6 \%$ v. $15.0 \%)$ and aged $50-64$ years $(27.4 \%$ v. $21.3 \%)$, although the CIs for these estimates again overlapped. One-year poststroke death rates were similar for First Nations and other people in Ontario among those aged more than 65 years or more ('Table 3 ). 


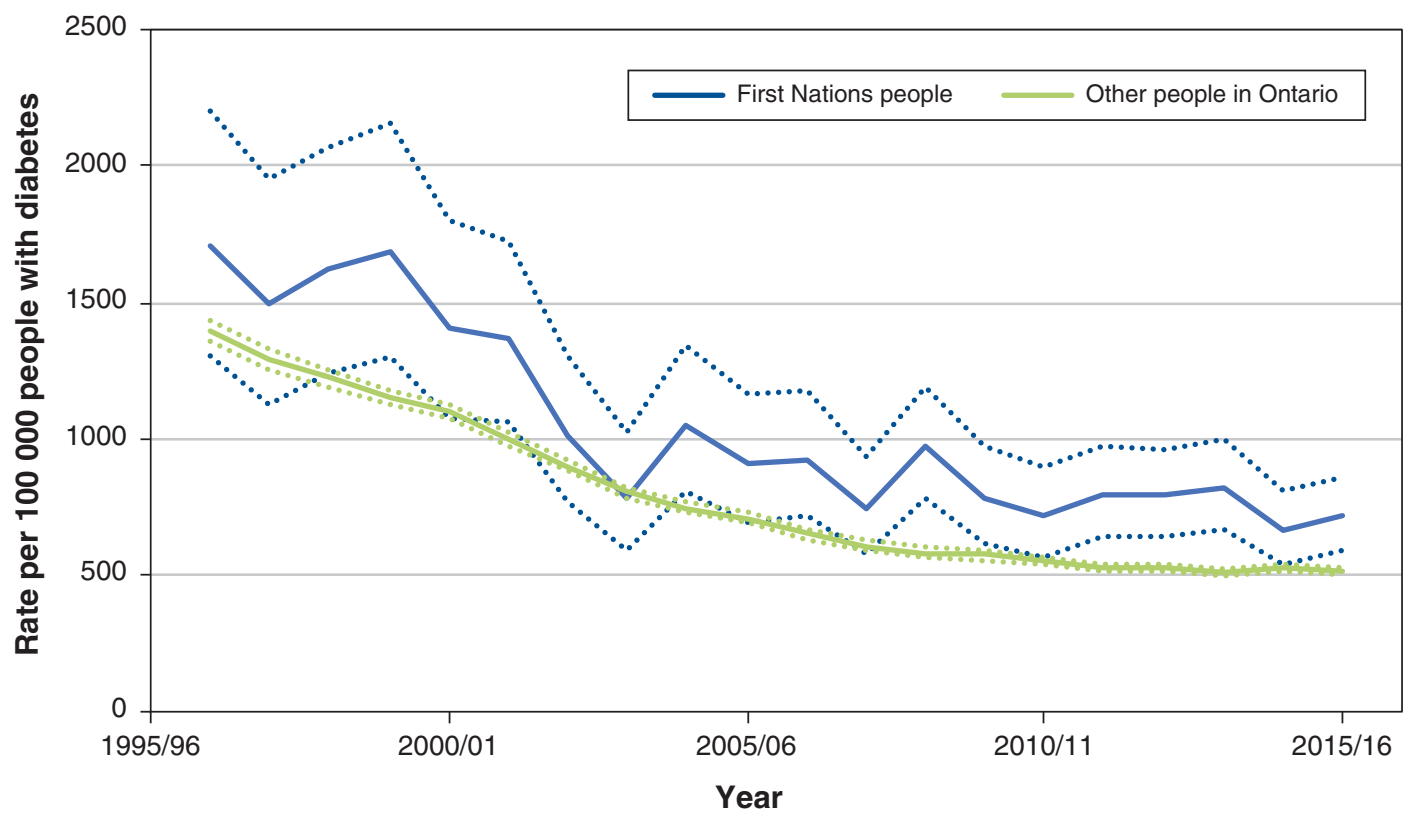

Figure 1: Age- and sex-standardized rate of hospital admission for acute stroke or transient ischemic attack among First Nations people and other people in Ontario per 100000 people with diabetes, Apr. 1, 1996, to Mar. 31, 2016. Dotted lines represent 95\% confidence intervals.

\begin{tabular}{|c|c|c|}
\hline \multirow[b]{2}{*}{ Variable } & \multicolumn{2}{|c|}{ Rate per $100000(95 \% \mathrm{Cl})$} \\
\hline & First Nations people & Other people in Ontario \\
\hline Overall & $641.2(539.8-756.2)$ & $540.2(527.7-552.9)$ \\
\hline \multicolumn{3}{|l|}{ Sex } \\
\hline Men & $667.0(518.0-845.6)$ & $555.4(537.8-573.4)$ \\
\hline Women & $619.0(485.2-778.3)$ & $523.8(506.1-542.0)$ \\
\hline \multicolumn{3}{|l|}{ Age, yr } \\
\hline 20-29 & $-^{*}$ & $42.0(18.2-82.8)$ \\
\hline $30-49$ & $271.0(154.9-440.1)$ & $99.0(85.3-114.2)$ \\
\hline $50-64$ & $776.4(605.2-980.9)$ & $281.8(266.5-297.8)$ \\
\hline $65-79$ & $837.7(611.0-1120.9)$ & $621.3(598.8-644.4)$ \\
\hline$\geq 80$ & $990.1(474.8-1820.8)$ & $1466.3(1411.7-1522.4)$ \\
\hline \multicolumn{3}{|l|}{ Event type } \\
\hline Stroke & $602.9(490.2-733.6)$ & $448.3(437.1-459.7)$ \\
\hline Transient ischemic attack & $151.5(97.2-225.2)$ & $75.4(70.9-80.2)$ \\
\hline
\end{tabular}

\section{Interpretation}

In this population-based study of people with diabetes in Ontario, we found that overall hospital admission rates for stroke or TIA declined between 1995/96 and 2015/16. However, in most years after 2005/06, admission rates for stroke or TIA were higher for First Nations people than other Ontarians. Compared to other Ontarians with diabetes 


\begin{tabular}{|c|c|c|}
\hline \multicolumn{3}{|c|}{$\begin{array}{l}\text { Table 3: Rates of processes of care and outcomes after acute stroke among First } \\
\text { Nations people and other people in Ontario with diabetes, Apr. 1, 2011, to Mar. 31, 2017* }\end{array}$} \\
\hline \multirow[b]{2}{*}{ Care/outcome† } & \multicolumn{2}{|c|}{ Point estimate, \% (95\% Cl) } \\
\hline & First Nations people & Other people in Ontario \\
\hline Neuroimaging $\ddagger$ & $94.6(85.9-100.0)$ & $96.0(94.2-97.9)$ \\
\hline Thrombolysis§ & $6.3(3.9-9.7)$ & $11.0(10.3-11.7)$ \\
\hline Carotid revascularization§ & $1.4(0.5-3.0)$ & $2.7(2.4-3.0)$ \\
\hline $\begin{array}{l}\text { Discharge to inpatient } \\
\text { rehabilitationๆ }\end{array}$ & $31.8(26.0-38.5)$ & $34.8(33.6-36.1)$ \\
\hline 7-d case fatality & $12.0(8.9-15.9)$ & $8.5(8.0-9.0)$ \\
\hline 30-d case fatality & $19.2(15.2-24.0)$ & $16.0(15.3-16.6)$ \\
\hline \multicolumn{3}{|l|}{ 1-yr case fatality } \\
\hline Overall & $33.8(28.2-40.2)$ & $28.1(27.1-29.1)$ \\
\hline \multicolumn{3}{|l|}{ Sex } \\
\hline Men & $34.3(26.8-43.2)$ & $32.9(31.9-33.9)$ \\
\hline Women & $31.9(24.9-40.1)$ & $37.9(36.8-39.1)$ \\
\hline \multicolumn{3}{|l|}{ Age, yr } \\
\hline $30-49$ & $28.6(15.6-47.9)$ & $15.0(12.7-17.7)$ \\
\hline $50-64$ & $27.4(20.4-35.9)$ & $21.3(20.1-22.6)$ \\
\hline $65-79$ & $37.2(28.0-48.4)$ & $33.4(32.3-34.5)$ \\
\hline$\geq 80$ & $51.1(32.4-76.7)$ & $49.9(48.3-51.5)$ \\
\hline \multicolumn{3}{|c|}{$\begin{array}{l}\text { Note: } \mathrm{Cl}=\text { confidence interval. } \\
\text { *All events (with the exception of age- and sex-specific case fatality) were age- and sex-standardized to the } 2001 \\
\text { Ontario population aged } 20 \text { years or more with diabetes. } \\
\text { †The denominator for brain imaging and thrombolysis included people admitted to hospital with events between } \\
\text { Apr. 1, 2012, and Mar. } 31,2017 \text {. The denominator for carotid revascularization, discharge to inpatient rehabilitation } \\
\text { and case fatality included those admitted to hospital between Apr. } 1,2011 \text {, and Mar. } 31,2016 \text {. } \\
\text { fComputed tomography or magnetic resonance imaging of the brain; calculated in those with any stroke or } \\
\text { transient ischemic attack (TIA). } \\
\text { §Calculated in those with ischemic stroke (TIA and hemorrhagic stroke excluded). } \\
\text { ๆCalculated in those with any stroke (TIA excluded). }\end{array}$} \\
\hline
\end{tabular}

and acute stroke, First Nations people were younger, were more likely to live in rural areas, were more likely to be female, had similar use of brain imaging, inpatient rehabilitation and carotid revascularization, and were less likely to be treated with thrombolysis. Although the point estimates for stroke case fatality were higher for First Nations people than for other Ontarians, the CIs for these estimates overlapped.

Temporal declines in stroke incidence have been reported in studies from other high-income countries. ${ }^{22}$ However, those declines were not consistent across regions and groups of patients, and stroke incidence has been increasing in lowand middle-income countries and among younger people in high-income countries. ${ }^{23,24}$ Regional variations in stroke incidence are generally attributed to differences in the prevalence and management of stroke risk factors such as hypertension, diabetes and atrial fibrillation. ${ }^{2}$ Our observed higher rates of hospital admission for stroke or TIA in First Nations people compared to other Ontarians suggest that targeted strokeprevention strategies, including the identification and modification of vascular risk factors, may be needed for First Nations groups with diabetes. Additional factors such as rurality and socioeconomic status can affect stroke risk, with diabetes being an important mediator of the association between socioeconomic deprivation and ischemic stroke risk. $^{25,26}$

A focus on the social and Indigenous-specific determinants of health, including the ongoing impact of colonization, is also needed to address the health of First Nations people. ${ }^{10,27}$ Our finding that admissions for stroke were particularly high for younger First Nations people with diabetes suggests a need to identify and address the causes of stroke in these younger adults, who may also have unique rehabilitation and reintegration needs after stroke and who face reduced employability and productivity during peak working years. ${ }^{28,29}$

Our finding of higher admission rates for stroke among Indigenous than among non-Indigenous people, particularly in younger age groups, is consistent with previous research from Australia. ${ }^{8,9,30}$ Although our observed stroke incidence rates are higher than those seen in the general population in Canada and elsewhere, ${ }^{31,32}$ similar rates were found in a previous study of people with diabetes in Ontario and presumably reflect the excess stroke risk associated with diabetes. ${ }^{33}$ 
In people with suspected acute stroke, rapid neuroimaging with computed tomography or magnetic resonance imaging is recommended to confirm the diagnosis and determine whether the stroke is ischemic or hemorrhagic. ${ }^{11,34}$ It is reassuring that almost all First Nations and other Ontarians underwent neuroimaging within 24 hours of presentation to hospital. However, First Nations people with ischemic stroke were less likely than other Ontarians to receive thrombolysis, which can improve outcomes after stroke..$^{35}$ Our data sources did not allow us to determine the reasons for this difference, and further research is needed to understand whether the lower observed rates of thrombolysis in First Nations people were due to appropriate patient selection based on presentation and clinical factors, lack of awareness of the need for rapid assessment, geographic distance to facilities with the capacity for neuroimaging and thrombolysis, patient preferences or other factors.

Inpatient rehabilitation is recommended for people with stroke and residual functional deficits who are able to participate in a rehabilitation program. ${ }^{36}$ In our study, overall rates of discharge to inpatient rehabilitation after acute stroke were similar in First Nations people and others with diabetes. However, our data sources did not have information on functional status after stroke, and so further work is needed to determine whether rates of discharge to rehabilitation are appropriate based on the level of disability in each group.

Although the CIs overlapped, point estimates for age- and sex-adjusted case fatality at 7,30 and 365 days after stroke were higher for First Nations people than for other Ontarians. Larger, sufficiently powered studies are needed to determine whether there are differences in stroke case fatality between First Nations people and other Ontarians.

\section{Limitations}

A number of study limitations merit comment. The Ontario Diabetes Database does not distinguish between type 1 and type 2 diabetes and identifies only people who seek health care and are diagnosed with diabetes. First Nations people who were not registered with the Indian Register, including those who were members of First Nations communities not recognized by the federal government, formed part of the non-First Nations group. We do not have information on the completeness of the Indian Register or on the characteristics of people who might have been excluded.

We studied only hospital admissions and do not have information for people with stroke who died before hospital arrival or who were seen in the emergency department and discharged without being admitted. We could not account for differences in proximity to stroke care facilities between First Nations people and other Ontarians, which may have affected admission rates, especially in those with TIA or minor stroke. Our available data sources did not include information on many indicators of the quality of stroke care delivery, such as the use of neurovascular imaging, mechanical thrombectomy, stroke unit care, dysphagia screening and medications for secondary stroke prevention. ${ }^{37}$

The lack of detailed clinical and sociodemographic data did not permit an analysis of the underlying reasons behind the observed differences in admission rates and thrombolysis use in First Nations people compared to other Ontarians, an assessment of the use of rehabilitation services stratified by disability or an analysis of the potential cultural-historic factors underlying our findings. We did not have information on many factors that may affect stroke incidence and outcomes, including the type, severity and duration of diabetes, stroke subtype and severity, and the presence of hyperglycemia at the time of presentation. In addition, we did not have information on other important stroke outcomes such as functional status and quality of life..$^{38}$

Our study used administrative data to identify baseline variables and outcomes, and, although the validity of these data sources is excellent for variables such as age, sex, stroke type and mortality, a full range of validation studies for all variables is not available. Finally, the relatively small sample of First Nations people with stroke may have provided inadequate power to detect differences in care and outcomes in some subgroups of patients.

\section{Conclusion}

Our findings suggest that First Nations people with diabetes are at increased risk for hospital admission for stroke or TIA compared to other Ontarians with diabetes and that these risks are particularly high for younger First Nations people. These findings may provide useful baseline data that can be used to inform the design of more detailed studies. Multifaceted interventions that address traditional risk factors along with Indigenous-specific determinants of health are needed to mitigate the risks and consequences of stroke in First Nations people with diabetes.

\section{References}

1. Benjamin EJ, Blaha MJ, Chiuve SE, et al.; American Heart Association Statistics Committee and Stroke Statistics Subcommittee. Heart disease and stroke statistics - 2017 update: a report from the American Heart Association (published errata in Circulation 2017;135:e646 and Circulation 2017;136:e196). Circulation 2017;135:e146-603.

2. O'Donnell MJ, Xavier D, Liu L, et al. Risk factors for ischaemic and intracerebral haemorrhagic stroke in 22 countries (the INTERSTROKE study): a casecontrol study. Lancet 2010;376:112-23.

3. Khoury JC, Kleindorfer D, Alwell K, et al. Diabetes mellitus: a risk factor for ischemic stroke in a large biracial population. Stroke 2013;44:1500-4.

4. Lee M, Saver JL, Hong KS, et al. Effect of pre-diabetes on future risk of stroke: meta-analysis. BM7 2012;344:e3564.

5. Shah AD, Langenberg C, Rapsomaniki E, et al. Type 2 diabetes and incidence of cardiovascular diseases: a cohort study in 1.9 million people. Lancet Diabetes Endocrinol 2015;3:105-13.

6. Turin TC, Saad N, Jun M, et al. Lifetime risk of diabetes among First Nations and non-First Nations people. CMA7 2016;188:1147-53.

7. Dyck R, Osgood N, Lin TH, et al. Epidemiology of diabetes mellitus among First Nations and non-First Nations adults. CMA7 2010;182:249-56.

8. Katzenellenbogen JM, Vos T, Somerford P, et al. Burden of stroke in indigenous Western Australians: a study using data linkage. Stroke 2011;42:1515-21.

9. You J, Condon JR, Zhao Y, et al. Stroke incidence and case-fatality among Indigenous and non-Indigenous populations in the Northern Territory of Australia, 1999-2011. Int 7 Stroke 2015;10:716-22.

10. King M, Smith A, Gracey M. Indigenous health part 2: the underlying causes of the health gap. Lancet 2009;374:76-85.

11. Boulanger JM, Lindsay MP, Gubitz G, et al. Canadian stroke best practice recommendations for acute stroke management: prehospital, emergency department, and acute inpatient stroke care, 6th edition, update 2018. Int 7 Stroke 2018;13:949-84.

12. Wein T, Lindsay MP, Côté R, et al. Canadian stroke best practice recommendations: secondary prevention of stroke, sixth edition practice guidelines, update 2017. Int 7 Stroke 2018;13:420-43. 
13. Table 051-0001. Population by year, by province and territory. Ottawa: Statistics Canada; updated 2019. Available: https://www150.statcan.gc.ca/t1/tbl1/en/ tv.action?pid=1710000501 (accessed 2018 June 11).

14. Slater M, Green ME, Shah B, et al. First Nations people with diabetes in Ontario: methods for a longitudinal population-based cohort study. CMAJ Open 2019;7:E680-8.

15. Hux JE, Ivis F, Flintoft V, et al. Diabetes in Ontario: determination of prevalence and incidence using a validated administrative data algorithm. Diabetes Care 2002;25:512-6.

16. Kokotailo RA, Hill MD. Coding of stroke and stroke risk factors using international classification of diseases, revisions 9 and 10. Stroke 2005;36:1776-81.

17. Austin PC, Shah BR, Newman A, et al. Using the Johns Hopkins' Aggregated Diagnosis Groups (ADGs) to predict 1-year mortality in population-based cohorts of patients with diabetes in Ontario, Canada. Diabet Med 2012;29: 1134-41.

18. Amarenco P; Steering Committee and Investigators of the TIAregistry.org Project. Five-year risk of stroke after TIA or minor ischemic stroke. $N$ Engl $\mathcal{F}$ Med 2018;379:1580-1.

19. Reeves M, Khoury J, Alwell K, et al. Distribution of National Institutes of Health stroke scale in the Cincinnati/Northern Kentucky Stroke Study. Stroke 2013;44:3211-3.

20. Walker J, Lovett R, Kukutai T, et al. Indigenous health data and the path to healing. Lancet 2017;390:2022-3.

21. Kralj B. Measuring "rurality" for purposes of health-care planning: an empirical measure for Ontario. Ont Med Rev 2000;67:33-52.

22. Krishnamurthi RV, Moran AE, Feigin VL, et al. Stroke prevalence, mortality and disability-adjusted life years in adults aged 20-64 years in 1990-2013: data from the Global Burden of Disease 2013 Study. Neuroepidemiology 2015;45:190-202.

23. Feigin VL, Krishnamurthi RV, Parmar P, et al. Update on the Global Burden of Ischemic and Hemorrhagic Stroke in 1990-2013: the GBD 2013 study. Neuroepidemiology 2015;45:161-76.

24. Seminog OO, Scarborough P, Wright FL, et al. Determinants of the decline in mortality from acute stroke in England: linked national database study of 795869 adults. BM7 2019;365:11778.

25. Kapral MK, Austin PC, Jeyakumar G, et al. Rural-urban differences in stroke risk factors, incidence, and mortality in people with and without prior stroke. Circ Cardiovasc Qual Outcomes 2019;12:e004973.

26. Bray BD, Paley L, Hoffman A, et al. Socioeconomic disparities in first stroke incidence, quality of care, and survival: a nationwide registry-based cohort study of 44 million adults in England. Lancet Public Health 2018:e185-93.

27. Greenwood M, de Leeuw S, Lindsay N. Challenges in health equity for Indigenous peoples in Canada. Lancet 2018;391:1645-8.

28. Ekker MS, Boot EM, Singhal AB, et al. Epidemiology, aetiology, and management of ischaemic stroke in young adults. Lancet Neurol 2018;17:790-801.

29. Vyas MV, Hackam DG, Silver FL, et al. Lost productivity in stroke survivors: an econometrics analysis. Neuroepidemiology 2016;47:164-70.

30. Balabanski AH, Newbury J, Leyden JM, et al. Excess stroke incidence in young Aboriginal people in South Australia: pooled results from two populationbased studies. Int 7 Stroke 2018;13:811-4.

31. Benjamin EJ, Muntner P, Alonso A, et al.; American Heart Association Council on Epidemiology and Prevention Statistics Committee and Stroke Statistics Subcommittee. Heart disease and stroke statistics - 2019 update: a report from the American Heart Association. Circulation 2019;139:e56-528.

32. Stroke in Canada: highlights from the Canadian Chronic Disease Surveillance System. Ottawa: Public Health Agency of Canada. Available: www.canada.ca/ en/public-health/services/publications/diseases-conditions/stroke-canada-fact -sheet.html (accessed 2020 Feb. 28).

33. Kapral M, Rothwell D, Fung K, et al. Diabetes and stroke. In: Hux JE, Booth GL, Slaughter PM, editors. Diabetes in Ontario: an ICES practice atlas. Toronto: Institute for Clinical Evaluative Sciences; 2003:151-63.

34. Wardlaw JM, Seymour J, Cairns J, et al. Immediate computed tomography scanning of acute stroke is cost-effective and improves quality of life. Stroke 2004;35:2477-83.

35. Emberson J, Lees KR, Lyden P, et al. Effect of treatment delay, age, and stroke severity on the effects of intravenous thrombolysis with alteplase for acute ischaemic stroke: a meta-analysis of individual patient data from randomised trials. Lancet 2014; 384:1929-35.
36. Hebert D, Lindsay MP, McIntyre A, et al. Canadian stroke best practice recommendations: stroke rehabilitation practice guidelines, update 2015 . Int 7 Stroke 2016;11:459-84.

37. Coutts SB, Wein TH, Lindsay MP, et al. Canadian stroke best practice recommendations: secondary prevention of stroke guidelines, update 2014. Int 7 Stroke 2015;10:282-91.

38. Salinas J, Sprinkhuizen SM, Ackerson T, et al. An international standard set of patient-centered outcome measures after stroke. Stroke 2016;47:180-6.

Affiliations: Department of Medicine (Kapral, Shah), University of Toronto; ICES (Kapral, Shah, Porter, Walker), Toronto, Ont.; Department of Family Medicine (Green, Frymire, Slater), Queen's University; ICES Queen's (Green, Griffiths, Frymire, Slater), Kingston, Ont.; Memory Keepers Medical Discovery Team (Jacklin), Department of Family Medicine and Biobehavioral Health, University of Minnesota Medical School Duluth, Duluth, Minn.; Chiefs of Ontario (Sutherland); School of Rural and Northern Health (Walker), Laurentian University, Sudbury, Ont.

Contributors: All of the authors contributed to the study conception and design, data acquisition, analysis and interpretation, and drafting the manuscript, revised the manuscript critically for important intellectual content. approved the final version to be published and agreed to be accountable for all aspects of the work.

Funding: Moira Kapral was supported by a Mid-Career Award from the Heart and Stroke Foundation of Canada. Michael Green was supported by the Brian Hennen Chair in Family Medicine, Queen's University. Morgan Slater was supported by a Health System Impact Fellowship from the Canadian Institutes of Health Research (CIHR). Jennifer Walker was supported by a Tier 2 Canada Research Chair in Indigenous Health. Funding was provided by the Ontario SPOR SUPPORT Unit, which is supported by CIHR and the Province of Ontario. This study was supported by ICES, which is funded by an annual grant from the Ontario Ministry of Health and Long-Term Care.

Acknowledgements: The authors' partners through the early design, implementation and final dissemination of this project were the Chiefs of Ontario. Their many contributions were key to the content and quality of the project. The authors acknowledge the members of the Patient Advisory Committee for providing insightful and thoughtful input; their advice made an important contribution in shaping the work. The authors also acknowledge the First Nations people from Big Grassy River First Nation, Alderville First Nation, Caldwell First Nation, Six Nations of the Grand River and Moose Cree First Nation with diabetes who shared their personal experiences.

Disclaimer: This study was supported by ICES, which is funded by an annual grant from the Ontario Ministry of Health and Long-Term Care (MOHLTC). The opinions, results and conclusions reported in this article are those of the authors and are independent from the funding sources. No endorsement by ICES or the Ontario MOHLTC is intended or should be inferred. Parts of this material are based on data or information compiled and provided by the Canadian Institute for Health Information (CIHI). However, the analyses, conclusions, opinions and statements expressed in the material are those of the authors and not necessarily those of CIHI.

Supplemental information: For reviewer comments and the original submission of this manuscript, please see www.cmajopen.ca/content/8/1/ E156/suppl/DC1. 